\title{
Dopamine receptor D3 gene and essential tremor in large series of German, Danish and French patients
}

\author{
Delia Lorenz ${ }^{1,9}$, Stephan Klebe ${ }^{1,9}$, Giovanni Stevanin ${ }^{2,3,4,9}$, Sandra Thier ${ }^{1}$, Almut Nebel $^{5}$, \\ Josué Feingold, ${ }^{2,6}$, Henrik Frederiksen ${ }^{7}$, Elodie Denis ${ }^{2}$, Kaare Christensen $^{7}$, \\ Stefan Schreiber ${ }^{5}$, Alexis Brice ${ }^{2,3,4,8}$, Günther Deuschl ${ }^{\star, 1,10}$ and Alexandra Dürr ${ }^{2,3,4,10}$
}

\begin{abstract}
${ }^{1}$ Department of Neurology, University Hospital Schleswig-Holstein, Campus Kiel, Kiel, Germany; ${ }^{2}$ Department of Genetics and Cytogenetics, AP-HP, Pitié-Salpêtrière Hospital, Paris, France; ${ }^{3}$ INSERM, UMR_S679, Paris, France; ${ }^{4}$ Université Pierre et Marie Curie-Paris 6, UMR_S679, Pitié-Salpêtrière Hospital, Paris, France; ${ }^{5}$ Institute of Clinical Molecular Biology, Christian-Albrechts-University Kiel, Kiel, Germany; ${ }^{6}$ Université Pierre et Marie Curie-Paris 6, EA 3974, Modelling in Clinical Research, Paris, France; ${ }^{7}$ The Danish Twin Registry, Epidemiology, Institute of Public Health, University of Southern Denmark, Odense, Denmark; ${ }^{8}$ AP-HP, Pitié-Salpêtrière Hospital, Federation of
\end{abstract} Neurology, Paris, France

The genetic causes of essential tremor (ET) seem to be heterogeneous. Recently, ET has been found associated with a functional variant (Ser9Gly) of the dopamine $D_{3}$ receptor (DRD3), located in the ETM1 locus on chromosome 3q13.3 described for the first time in 1997. We examined this variant in three different populations from Germany, Denmark and France. We undertook an association study of the Ser9Gly variant in 202 cases with a familial history from unrelated families with ET, 97 cases with isolated non-familial ET and 528 healthy controls. In addition, linkage and segregation analyses were carried out in 22 ET families. The distribution of genotypes and allele frequencies showed no significant differences in the whole sample and in a subanalysis of familial and sporadic cases. Age at onset of tremor, tremor duration and tremor severity did not show an association with the genotype. In addition, the DRD3 variant was not found linked to the disease in a subset of informative ET families. We did not find a significant association of the DRD3 variant with ET nor linkage to the DRD3 receptor in German, Danish and French ET patients and families, suggesting that it is unlikely to be a causal factor for ET.

European Journal of Human Genetics (2009) 17, 766-773; doi:10.1038/ejhg.2008.243; published online 17 December 2008

Keywords: essential tremor; ETM1; DRD3 receptor

Introduction

Essential tremor (ET) is one of the most common movement disorders and shows a heterogeneous pheno-

${ }^{*}$ Correspondence: Professor Dr G Deuschl, Department of Neurology, Universitätsklinikum Schleswig-Holstein, Campus Kiel, Schittenhelmstr. 10, Kiel 24105, Germany.

Tel: + 49431597 8500; Fax: + 494315978502 ;

E-mail: g.deuschl@neurologie.uni-kiel.de

${ }^{9}$ These authors contributed equally to this work.

${ }^{10}$ These authors contributed equally as senior authors to this work.

Received 24 June 2008; revised 10 November 2008; accepted 13 November 2008; published online 17 December 2008 type. A positive family history has long been recognized and is reported in $17-100 \%$ of ET patients. ${ }^{1}$ Segregation analysis reveals that ET transmission might be compatible with an autosomal-dominant mode of inheritance. ${ }^{2}$ However, a large proportion of ET patients present as isolated cases, and in that case, ET is considered not to be a single gene disorder but a complex disease requiring interactions of environmental and genetics factors with low penetrance. ${ }^{3-5}$ At least three chromosomal loci (ETM) have been identified by linkage analysis so far. ETM1 has been mapped in Icelandic families on chromosome $3 q_{13}{ }^{6}$ ETM2 in North American families 
on chromosome 2p22-p25 and ETM3 has been identified in North American families on chromosome $6 \mathrm{p} 23 .^{8}$

The $10 \mathrm{cM}$ interval of the ETM1 region contains approximately 70 genes according to different electronic sources (National Centre of Biological Investigation (NCBI); Ensembl genome browser), including the dopamine $\mathrm{D}_{3}$ receptor (DRD3) gene in which three synonymous and one non-synonymous SNP have been reported. Linkage and association to the non-synonymous variant (Ser9Gly, A $\rightarrow \mathrm{G}$ ) of the DRD3 gene has recently been shown in a small sample of 30 French familial ET cases and a larger American sample of ET patients $(n=276)$ with Gly homozygous patients presented with more severe and/or earlier onset forms of the disease. ${ }^{9,10}$ However, the effect in the Americans was much smaller (odds ratio $(\mathrm{OR})=1.35$ with allelic $P$-value $=0.039)$ than in the French sample alone $(\mathrm{OR}=2.5$, allelic $P$-value $=0.007)$. Furthermore, in vitro studies have shown an increase of the dopaminemediated cAMP response and of mitogen-associated protein kinase with the $G$ allele, so that an increase in dopamine affinity by the Gly9 variant was hypothesized. However, two replication studies did not find a significant association of the Gly allele with ET in Asian ${ }^{11}$ and American samples. ${ }^{12}$ To date, the Ser9Gly DRD3 polymorphism has only been investigated in one linkage-based study in French families ${ }^{9}$ but has not been investigated in other European ET samples in an association-based study design so far. Therefore, we performed linkage and association analysis of the DRD3 variant in 299 unrelated ET index patients and 528 controls of German, Danish and French origin.

\section{Patients and methods \\ Patients}

For the association study, 299 unrelated ET index patients were included from two centres in Kiel ( $n=147$, including 28 Danish patients) and Paris $(n=52)$ (Table $1 \mathrm{a}$ and $1 \mathrm{~b})$. The Danish sample was initially recruited for a twin study of ET within the framework of the Longitudinal Study of Aging of Danish Twins. ${ }^{13}$ All participants gave their informed consent. This study was approved by the German (reference no. A143/00), Danish (reference no. 20010177) and French (reference no. 04-06-08) Ethical Committees. Two hundred and two patients described a positive family history (135 German; 49 French; 18 Danish).

Familial segregation and linkage analysis of the DRD3 variant was performed in 22 ET families (16 French; 4 German; 2 Danish), selected among the 202 familial cases considering 89 definite and probably affected individuals (66 French; 17 German; 6 Danish), 15 patients with a possible status (8 German; 7 French) and 68 unaffected individuals (38 French; 24 German; 6 Danish).

In 15 of these families (12 French families and 3 German families), the intervals between markers D2S224 and D2S405 (2p22-p25; ETM2) and D6S202 and D6S289 (6p23; ETM3) were previously excluded by haplotype reconstructions (data not shown, ETM2: D2S224; D2S2150; D2S144; D2S405; ETM3: D6S202; D6S1279; D6S1006; D6S289).

Table 1a Clinical characteristics of samples with familial essential tremor from three different countries

\begin{tabular}{|c|c|c|c|c|}
\hline Clinical features & German samples & French samples & Danish samples & All \\
\hline $\begin{array}{l}\text { Number of index cases } \\
\text { Men/women } \\
\text { Age at examination, years, } \\
\text { mean } \pm \text { SD (range) }\end{array}$ & $\begin{array}{c}135 \\
88 / 47 \\
59.1 \pm 14.6(18-84)\end{array}$ & $\begin{array}{c}49 \\
22 / 27 \\
52.9 \pm 18.6(19-84)\end{array}$ & $\begin{array}{c}18 \\
9 / 9 \\
75.2 \pm 5.1(70-89)\end{array}$ & $\begin{array}{c}202 \\
119 / 83 \\
58.7 \pm 16.1(18-89)\end{array}$ \\
\hline $\begin{array}{l}\text { Age at onset, years, mean } \pm \text { SD (range) } \\
\text { AA } \\
\text { AG } \\
\text { GG }\end{array}$ & $\begin{array}{r}29.7 \pm 19.2(5-75) \\
29 \pm 19.3(5-74) \\
30.2 \pm 19.2(5-75) \\
30.2 \pm 20.4(2-65)\end{array}$ & $\begin{array}{l}28.6 \pm 19.2(5-70) \\
27.4 \pm 21.6(5-70) \\
29.1 \pm 18.4(6-60) \\
31.3 \pm 18.7(14-56)\end{array}$ & $\begin{array}{l}\text { NA } \\
\text { NA } \\
\text { NA } \\
\text { NA }\end{array}$ & $29.4 \pm 19.2(5-75)$ \\
\hline $\begin{array}{l}\text { Tremor severity }{ }^{\mathrm{a}} \text {, mean } \pm \text { SD }{\text { (range })^{\mathrm{b}}}^{\text {AA }} \\
\text { AG } \\
\text { GG }\end{array}$ & $\begin{array}{l}7.2 \pm 3.7(2-21) \\
7.4 \pm 3.3(3-17) \\
7.5 \pm 4.2(2-21) \\
5 \pm 1.2(4-8)\end{array}$ & $\begin{array}{l}11.5 \pm 6.2(2-26) \\
8.1 \pm 5.7(2-22) \\
13.5 \pm 6(3-26) \\
13.3 \pm 4.2(10-18)\end{array}$ & $\begin{array}{l}7.1 \pm 2.6(3-12) \\
5.3 \pm 1.8(3-8) \\
7.8 \pm 2.3(5-11) \\
9.3 \pm 3.1(6-12)\end{array}$ & $8.2 \pm 4.7(2-26)$ \\
\hline $\begin{array}{l}\text { Tremor duration, years, mean } \pm \text { SD (range) } \\
\text { AA } \\
\text { AG } \\
\text { GG }\end{array}$ & $\begin{array}{r}28.4 \pm 16.3(5-60) \\
31 \pm 16.9(7-60) \\
28.1 \pm 16.7(5-60) \\
21.7 \pm 11.9(5-40)\end{array}$ & $\begin{array}{r}25.8 \pm 15.5(3-69) \\
29.4 \pm 18.5(3-69) \\
23.2 \pm 13.3(7-55) \\
27 \pm 16.1(14-50)\end{array}$ & $\begin{array}{l}\nabla \\
\nabla \\
\nabla \\
\nabla\end{array}$ & $27.6 \pm 16.1(3-69)$ \\
\hline Alcohol responsiveness of tremor (\%) & $81(60)$ & NA & $7(38.9)$ & $88(43.6)$ \\
\hline
\end{tabular}

NA, not available.

${ }^{a}$ By Part A of the Fahn-Burke-Marsden tremor scale 16, $\nabla$ in all Danish twins tremor duration $\geq 5$ years.

${ }^{b}$ No significant difference among each nation. 
Table 1b Clinical characteristics of samples with 'apparently' sporadic essential tremor from three different countries

\begin{tabular}{|c|c|c|c|c|}
\hline Clinical features & German samples & French samples & Danish samples & All \\
\hline $\begin{array}{l}\text { Number of index cases } \\
\text { Men/women } \\
\text { Age at examination, years, } \\
\text { mean } \pm S D \text { (range) }\end{array}$ & $\begin{array}{c}84 \\
49 / 35 \\
61 \pm 15.7(17-91)\end{array}$ & $\begin{array}{c}3 \\
2 / 1 \\
77 \pm 1.4(76-78)\end{array}$ & $\begin{array}{c}10 \\
6 / 4 \\
75.9 \pm 5.6(70-86)\end{array}$ & $\begin{array}{c}97 \\
57 / 40 \\
62.4 \pm 15.7(17-91)\end{array}$ \\
\hline $\begin{array}{l}\text { Age at onset, years, } \\
\text { mean } \pm \text { SD (range) } \\
\text { AA } \\
\text { AG } \\
\text { GG }\end{array}$ & $\begin{array}{l}30.2 \pm 20.9(2-80) \\
29.4 \pm 19.9(10-75) \\
32.7 \pm 21.7(5-80) \\
22.4 \pm 25.2(2-65)\end{array}$ & $\begin{array}{l}42 \pm 31.1(20-64) \\
42 \pm 31.1(20-64) \\
\quad-\end{array}$ & $\begin{array}{l}\text { NA } \\
\text { NA } \\
\text { NA } \\
\text { NA }\end{array}$ & $30.6 \pm 21.1(2-80)$ \\
\hline $\begin{array}{l}\text { Tremor severity }{ }^{\mathrm{a}} \text {, mean } \pm \text { SD } \text { (range) }^{\mathrm{b}} \\
\text { AA } \\
\text { AG } \\
\text { GG }\end{array}$ & $\begin{array}{r}7.3 \pm 4.2(2-26) \\
7.4 \pm 4.8(3-26) \\
7.2 \pm 3.6(2-16) \\
8 \pm 3.3(4-13)\end{array}$ & $\begin{array}{l}17.5 \pm 0.7(17-18) \\
17.5 \pm 0.7(17-18) \\
-\end{array}$ & $\begin{array}{l}5.4 \pm 1.9(3-8) \\
5.7 \pm 2.1(3-8) \\
7 \pm 0(7) \\
4 \pm 0(4)\end{array}$ & $7.4 \pm 4.3(2-26)$ \\
\hline $\begin{array}{l}\text { Tremor duration, years, } \\
\text { mean } \pm \text { SD (range) } \\
\text { AA } \\
\text { AG } \\
\text { GG } \\
\text { Alcohol responsiveness of tremor }(\%)\end{array}$ & $\begin{array}{c}29.4 \pm 18.4(5-70) \\
30.9 \pm 18.2(5-70) \\
27.2 \pm 19.4(5-60) \\
31.4 \pm 16.9(12-50) \\
\quad 35(41.7)\end{array}$ & $\begin{array}{c}35 \pm 32.5(12-58) \\
35 \pm 32.5(12-58) \\
\frac{-}{N A}\end{array}$ & $\begin{array}{c}\nabla \\
\nabla \\
\nabla \\
5(55.5)\end{array}$ & $29.5 \pm 18.6(5-70)$ \\
\hline
\end{tabular}

NA, not available.

${ }^{a}$ By Part A of the Fahn-Burke-Marsden tremor scale 16, $\nabla$ in all Danish twins tremor duration $\geq 5$ years.

${ }^{\mathrm{b}}$ No significant difference among each nation.

Controls There were 528 unrelated healthy controls, 299 men and 229 women. They were from Germany $(n=311$, mean age at examination $68.8 \pm 5.5$ years), ${ }^{14}$ from Denmark ( $n=52$, aged above 69 years at the time of examination) and from France $(n=165$, mean age at examination $63.2 \pm 9.2$ years). None of the controls showed any clinical signs of ET. All controls were screened negative for ET either by a screening procedure for ET (all Danish and German controls, $n=311)^{15}$ or they underwent a neurological examination (all French controls).

\section{Neurological examination and tremor diagnosis}

The clinical visits included anamnestic data on age at onset (AAO), duration and family history of tremor and a complete neurological examination by a movement disorders specialist. Tremor severity was rated by using the Fahn-Tolosa-Marin tremor scale, part A. ${ }^{16}$ ET was diagnosed on the three levels of certainty as defined by the consensus criteria of the Tremor Investigation Group. ${ }^{17}$ Only patients with definite and probable ET were included in the genetic analysis. Familial ET was defined as the presence of at least another first-degree relative of the index case affected with ET.

\section{DRD3 genotyping and sequencing}

DNA was extracted from blood samples using a standard protocol. Genotyping of the Gly9Ser variant (rs 6280), in the coding region of the DRD3 receptor, was performed in German and Danish unrelated ET patients $(n=247)$ and all
528 controls for the association study. In the 52 French index patients, all 7 coding exons of the DRD3 gene and their flanking splice sites with at least $50 \mathrm{bp}$ of intronic sequence on each side were sequenced.

Briefly, samples were PCR amplified with ABI 9700 PCR machines (Applied Biosystems, Foster City, USA). TaqMan SNP genotyping assay on ABI 7900 fluorometers or direct sequencing using the BigDye chemistry on ABI 3730 were used according to the instructions of the manufacturer (Applied Biosytems) as previously described. ${ }^{18-20}$ PCR primers and annealing conditions are available on request.

\section{Microsatellite genotyping}

For linkage analysis, four microsatellite markers (ETM1: D3S1552; D3S3652; D3S1278; D3S3641) covering a segment of approximately $45 \mathrm{cM}$ including the ETM1 region, ${ }^{6}$ centred on marker D3S1267, were amplified using one fluorescently labeled primer, and the fragments were resolved on an ABI-3730 sequencer (Applied Biosystems). Genotypes were determined with GeneMapper 4.0 software (Applied Biosystems).

\section{Statistical analysis}

The genotype and allele frequency between ET cases and controls were compared using the $\chi^{2}$-test. Both groups were tested for Hardy-Weinberg equilibrium. Statistical significance was defined at $P<0.05$. Analysis of variance was used to test for statistical significance for the between-patient factor 'genotype' and the within-patient factors 'age of 
onset, tremor duration and tremor severity'. Considering the whole sample and a frequency of $32 \%$ of the allele at risk $(G)$, the statistical power of this association study was $80 \%$ with an assumed OR of 1.6 and $99 \%$ with an OR of 2.5 analysed by the 'Fisher's exact' test. Bonferroni correction was used because of multiple comparisons (six tests).

For linkage analysis of patients with a positive family history, pairwise LOD scores of the Ser9Gly variant were calculated in 22 families using the MLINK program of the computer package FASTLINK. ${ }^{21,22}$ The disease was considered as an autosomal-dominant trait, assuming a penetrance of $90 \%$, a phenocopy rate of $1 \%$, a mutation frequency of 0.05 and identical recombination fractions for males and females. Patients with a possible ET were considered as having an unknown status, whereas definite and probably affected patients were considered as affected.

\section{Results}

Overall clinical characteristics of the three populations studied are shown in Table 1A (familial ET) and Table 1B (isolated non familial ET). Mean age at examination was 58.7 years (SD 16.1, range 17-91) in all ET patients and 66.9 years (SD 6.8, range 36-93) in controls with a similar gender distribution (male/female, 176/123 and 299/229). Tremor duration was 27.93 years (SD 16.1, range 3-69) as a mean and the mean age of tremor onset was 29.8 years (SD 20 , range $2-80$ ) in all.

The age at tremor onset $(P=0.96)$ and sex ratio $(P=0.141)$ were not statistically different between the three populations. The age at examination did shown a significant difference $(P=0.01)$ between the groups that was due to the older age in the Danish sample.

\section{Linkage and association studies}

Association studies We first looked at an association of the DRD3 variant in our ET groups. Distributions of the genotypes in ET and control groups were in HardyWeinberg equilibrium. Genotype and allele frequency of the Gly9 allele in the whole study sample $(n=299)$ showed no difference between ET patients and controls. Similarly, in subanalyses of ET patients without $(n=97)$ or with a positive family history $(n=202)$, no differences between ET patients and healthy controls were found. Regarding the largest population of patients with a positive family history from Germany $(n=135)$, the same negative result was obtained. On the contrary, the French samples with a positive family history $(n=49)$ alone showed a slightly significant association at both the allele and genotype levels (allelic $P$-value $=0.046$ and genotypic $P$-value $=0.026)$. After correction for multiple comparisons the association did not remain significant (Tables 2A and $2 \mathrm{~B})$.

As there was no evidence of heterogeneity between different ethnicities (see results of $\chi^{2}$-test in Table 3 ), the already published French, ${ }^{10}$ Asian $^{11}$ and American ${ }^{10,12}$ samples were added to our whole collection of ET patients. This yielded still no significant association (Table 3 ).

Linkage analysis with the Ser9Gly variant in 22 families Segregation of the variant was excluded in three families (ie, at least two patients carrying AA and GG genotypes) and was compatible with the transmission of the disease with allele $\mathrm{G}$ in $18 \%(n=4$, two of French ancestry) and with allele A in 59\% $(n=13$, including 10 of French ancestry), whereas two of the families were not informative (Figure 1), contrasting with a previous study showing allele $\mathrm{G}$ segregating in all French kindreds. ${ }^{10}$

Table 2A Genotype frequencies comparison between ET patients and controls according to the country and to family history

\begin{tabular}{|c|c|c|c|c|c|c|}
\hline \multirow[t]{2}{*}{ Patients } & \multicolumn{3}{|c|}{ Genotype frequencies } & \multirow[t]{2}{*}{$\begin{array}{c}\text { Statistical } \\
\text { comparison }^{\mathrm{a}}\end{array}$} & \multirow[t]{2}{*}{$\begin{array}{l}\text { P-value } \\
\left(\chi^{2}\right)\end{array}$} & \multirow[t]{2}{*}{$\begin{array}{l}\text { P-value } \\
\text { corrected }^{\mathrm{b}}\end{array}$} \\
\hline & $\begin{array}{c}A A(\text { Ser9Ser) } \\
(\%)\end{array}$ & $\begin{array}{c}A G(\operatorname{Ser} 9 G / y) \\
(\%)\end{array}$ & $\begin{array}{c}G G(\text { (Gly9G/y) } \\
(\%)\end{array}$ & & & \\
\hline Controls (German/Danish/French) (1) & $248(47)$ & $226(43)$ & $54(10)$ & - & - & \\
\hline All ET (German/Danish/French) (2) & $131(44)$ & $136(45)$ & $32(11)$ & $(1)-(2)$ & 0.68 & \\
\hline $\begin{array}{l}\text { German/Danish/French ET without family } \\
\text { history (3) }\end{array}$ & $50(52)$ & $37(38)$ & $10(10)$ & $(1)-(3)$ & 0.68 & \\
\hline German ET with family history (5) & $62(46)$ & $59(44)$ & $14(10)$ & - & - & \\
\hline German controls (6) & $145(47)$ & $131(42)$ & $35(11)$ & $(5)-(6)$ & 0.94 & \\
\hline French ET with family history (7) & $12(25)$ & $32(65)$ & $5(10)$ & - & - & \\
\hline French controls ( 8 ) & $75(45)$ & $74(45)$ & $16(10)$ & $(7)-(8)$ & 0.0262 & $0.16^{\mathrm{b}}$ \\
\hline
\end{tabular}

Genotypes in both patients and controls were in Hardy-Weinberg equilibrium.

${ }^{\text {a }}$ Statistical comparison of the different numbered case/control groups.

${ }^{\mathrm{b}}$ Correction for multiple testing (six tests)

Bold values represents $P$-value $<0.05$ 
Table 2B Allele frequencies comparison between ET patients and controls according to the country and family history

\begin{tabular}{|c|c|c|c|c|c|}
\hline \multirow[t]{2}{*}{ Patients } & \multicolumn{2}{|c|}{ Allele frequencies } & \multirow[t]{2}{*}{$\begin{array}{c}\text { Statistical } \\
\text { comparison }^{\text {a }}\end{array}$} & \multirow[t]{2}{*}{ P-value $\left(\chi^{2}\right)$} & \multirow[t]{2}{*}{$\begin{array}{l}\text { P-value } \\
\text { corrected }^{\mathrm{b}}\end{array}$} \\
\hline & $A(\%)$ & $G(\%)$ & & & \\
\hline Controls (German/Danish/French) (1) & $722(68)$ & $334(32)$ & - & - & \\
\hline All ET (German/Danish/French) (2) & $398(67)$ & $200(33)$ & $(1)-(2)$ & 0.45 & \\
\hline German/Danish/French ET without family history (3) & $137(71)$ & $57(29)$ & $(1)-(3)$ & 0.54 & \\
\hline German/Danish/French ET with family history (4) & $261(65)$ & $143(35)$ & $\begin{array}{l}(1)-(4) \\
(3)-(4)\end{array}$ & 0.17 & \\
\hline German ET with family history (5) & $183(68)$ & $87(32)$ & - & - & \\
\hline German controls (6) & $421(68)$ & $201(32)$ & $(5)-(6)$ & 0.97 & \\
\hline French ET with family history (7) & $56(57)$ & $42(43)$ & - & - & \\
\hline French controls (8) & $224(68)$ & $106(32)$ & $(7)-(8)$ & 0.046 & 0.39 \\
\hline
\end{tabular}

Genotypes in both patients and controls were in Hardy-Weinberg equilibrium.

${ }^{a}$ Statistical comparison of the different numbered case/control groups.

${ }^{\mathrm{b}}$ Correction for multiple testing (six tests).

Table 3 Comparison between genotype frequencies in the present and previous studies in initial series, ${ }^{10}$ Asian 11 and American 12 populations with familial essential tremor

\begin{tabular}{|c|c|c|c|c|}
\hline \multirow[t]{2}{*}{ Patients } & \multicolumn{3}{|c|}{ Genotypes (\%) } & \multirow[t]{2}{*}{ P-value $\left(\chi^{2}\right)$} \\
\hline & $A A$ & $A G$ & GG & \\
\hline \multicolumn{5}{|l|}{ ET patients } \\
\hline Asian sample ${ }^{11}$ & $72(44)$ & $76(47)$ & $15(9)$ & d.f.: 8 \\
\hline American sample ${ }^{12}$ & $92(39)$ & $111(47)$ & $34(14)$ & $P=0.314$ \\
\hline Initial French sample ${ }^{10}$ & $7(23)$ & $18(60)$ & $5(17)$ & \\
\hline Initial American sample ${ }^{10}$ & $124(45)$ & $117(42)$ & $35(13)$ & \\
\hline German/Danish/French sample & $248(47)$ & $226(43)$ & $54(10)$ & $\chi^{2}=13.789$ \\
\hline Asian sample ${ }^{11}$ & $85(44)$ & $87(45)$ & $20(11)$ & d.f.: 8 \\
\hline American sample ${ }^{12}$ & $55(45)$ & 47 (39) & $19(16)$ & $P=0.087$ \\
\hline Initial French sample ${ }^{10}$ & $30(60)$ & $14(28)$ & $6(12)$ & \\
\hline Initial American sample $e^{10}$ & $93(51)$ & $81(44)$ & $10(5)$ & \\
\hline
\end{tabular}

Accordingly, linkage of the Ser9Gly variant generated a combined pairwise LOD score of -7.16 ranging from -1.85 to +0.67 at $\theta=0$, when considering definite and probable ET patients (data not shown). The entire ETM1 region could be excluded by haplotype analysis using ETM1 flanking markers, in five families, including two of the families with slightly positive LOD scores with the Ser9Gly variant, thus indicating further genetic heterogeneity in these kindreds. All of these five families were former excluded for the ETM2 and ETM3 locus, respectively.

\section{Correlation between genotype and clinical data}

Age at onset, tremor duration and tremor severity for the different genotypes are shown in Table 1A and 1B. When all samples were taken into account or when analysing the largest series of patients only, the DRD3 genotypes (AA, AG and GG) did not affect significantly the AAO (German sample, $P=0.786$; French sample, $P=0.925)$, tremor duration (German sample, $P=0.255$; French sample, $P=0.513$ ) or tremor severity (German sample, $P=0.561$; French sample, $P=0.98$ ).

\section{Discussion}

In our extended study of the Ser9Gly variant of the DRD3 receptor in 299 unrelated ET patients and 528 controls of German, French and Danish origin, no significant differences of the genotype or allele frequencies between cases and controls were found. As the frequency of ET cases with a positive family history seems to be an important risk factor for the development of the disease, we analysed the two groups separately ( $n=202$ with and $n=97$ without a positive family history for ET) and found no differences between ET cases with or without positive family histories and controls. Only the small subset of French ET cases with a positive family history generated a slightly statistically significant result for the Ser9Gly variant at the allele and genotype levels and can most likely be attributed to an excess of heterozygotes among the cases. Surprisingly, this 

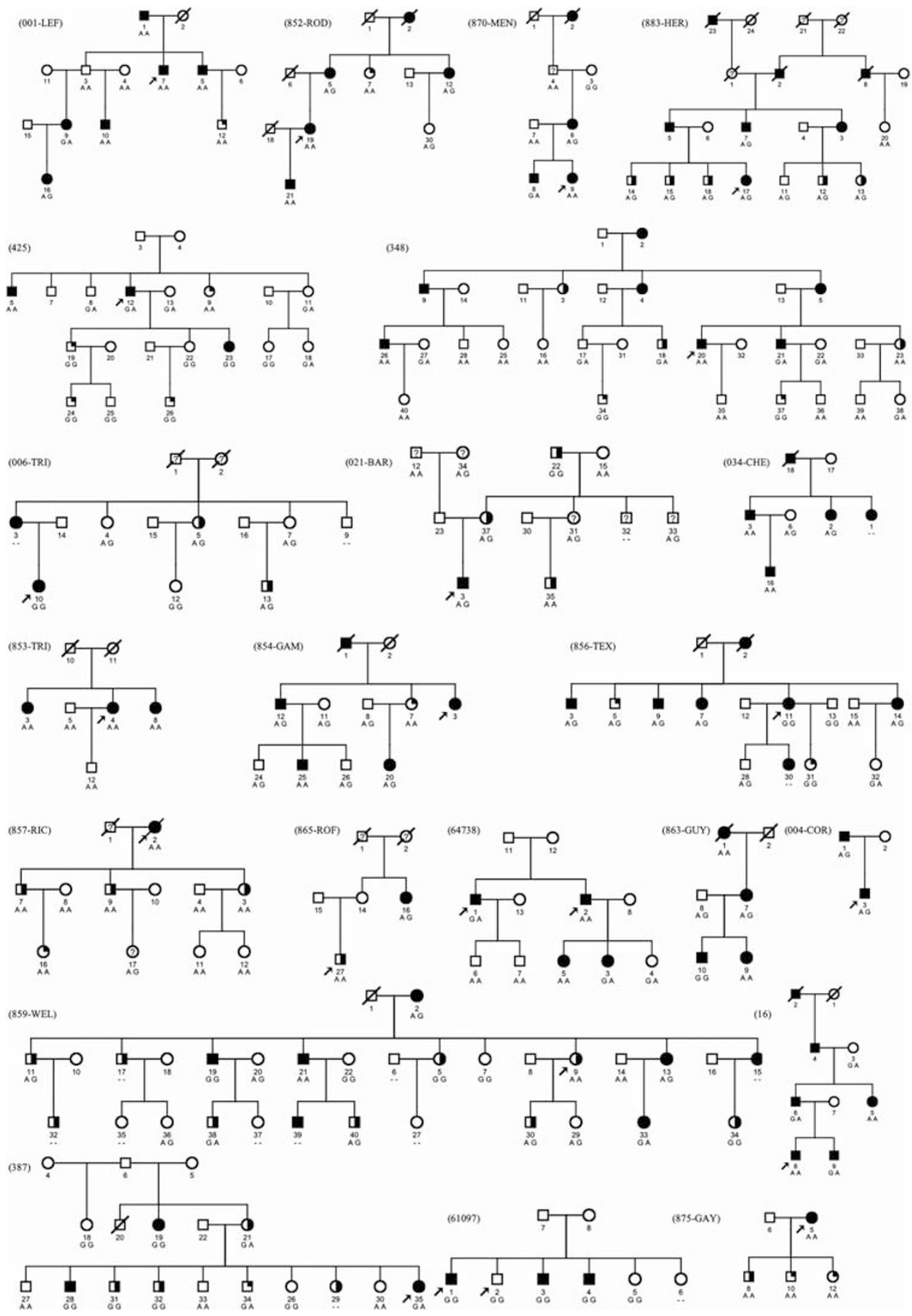

Figure 1 Pedigrees of essential tremor (ET) families used in this study. Definite ET patients are represented by solid squares and circles, probable ET by half black and possible ET by quarter black symbols, patients with unclear affection status are represented by an open symbol with a question mark and unaffected individuals are represented by an open symbol.

result was not significant for the Gly9 homozygotes and nevertheless was no more significant after correction for multiple testing. This leaves open the possibility that in some families the Ser9Gly polymorphism represents a modifier gene but its causal role can be mostly excluded in our series, provided that our study has $80 \%$ power to detect an OR as small as 1.6. Furthermore, in contrast to former studies that revealed the Gly9 allele as the risk variant, ${ }^{9,10}$ in most French kindreds allele $\mathrm{A}$ was the cosegregating allele. 
Finally, pairwise LOD scores and haplotype reconstructions in a subset of ET families of French, German and Danish origin with the Ser9Gly variant ruled out linkage between the DRD3 polymorphism and ET. Of note, no other variant in the DRD3 gene was found by direct sequencing of 52 French ET patients (data not shown). This is in line with the results of the initial French study, where no further non-synonymous variants, except the Ser9Gly, and no variants in splice junctions or the promoter region were found by sequencing a total of $5098 \mathrm{bp}$ in nine probands ( $n=3$ of each genotype). ${ }^{10}$

Our results are in agreement with the previous findings in Asian and American samples. ${ }^{11,12}$ Interestingly, the combination of both studies with ours firmly excludes an association of the Ser9Gly polymorphism with ET (Table 3). In addition, our results exclude linkage between this DRD3 polymorphism and ET in most informative families in contrast to the previous report showing cosegregation in 23 out of 30 French families with ET. ${ }^{9,10}$ There is no evidence for a selection bias, as patients originated from various parts of France. Nevertheless and as most kindreds shared allele A, we cannot exclude a limited number of founders in France. Possible causes for the absence of association and linkage in our series in contrast to the positive result in the American ET population ${ }^{9,10}$ may be some kind of population stratification due to a heterogeneous ethnic origin in the American ET population and the consequence of the use of a larger sample mainly of controls in our series. In addition, the AAO and the severity of ET in our samples did not differ according to the genotypes as shown in the previous report. ${ }^{10}$

The DRD3 gene is located within the originally described ETM1 locus. The linkage peak markers of the ETM1 locus, D3S1278 and D3S1267, are in 1 and $10 \mathrm{Mb}$ distance from the DRD3 gene, respectively. ${ }^{6}$ The ETM1 locus was originally described in 16 Icelandic families, a genetic isolate, ${ }^{6}$ and it has not been reported whether the Ser9Gly variant cosegregates with ET in these families.

Although ET has been assumed as a familial disorder with an apparent autosomal-dominant mode of inheritance already many years ago, ${ }^{23}$ the genetic analyses of the last 10 years showed that there is not only one simple 'ET

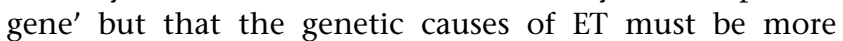
complex and/or heterogeneous. Recently, non-Mendelian transmission of ET was proposed as the proportion of affected ET patients was higher than the expected 50\% in four ET families. ${ }^{24}$ This finding is consistent with two French families of our series, which were excluded for the known ET loci, and in which $>50 \%$ of the offspring also suffered from ET. The reasons for these higher than expected ratio of affected offspring might be environmental factors with phenocopies within one family, bilineal transmission, digenic or multigenic risk accumulation with different combinations of polymorphisms playing minor roles or having modifying rather than causal properties.
Despite the strong familial aggregation of ET recognized as a dominant condition, linkage studies failed to lead to causative genes so far, which might be due to some underlying but unrecognized clinical heterogeneity. Our samples were assessed as consistent as possible because only three physicians have performed the diagnosis and for the control group individuals with advanced age were preferred. Clinical criteria for the diagnosis of ET seem insufficient to detect heterogeneity in families by distinguishing phenocopies from family-related cases. Therefore, association studies with a candidate gene approach need to be carefully interpreted. On the other side, genome-wide association studies (GWAS) are able to detect small effects, are independent of classical genetic models and take multiple genetic and environmental factors into account. GWAS, using better-defined ET subtypes according to additional clinical criteria, neurophysiologic and imaging results and treatment response orientated classifications, might be an appropriate genetic approach to analyse a heterogeneous disease such as ET.

In conclusion, we were not able to show neither a significant association nor linkage of the DRD3 variant with ET in a large number of Caucasian ET patients and families in our samples from three different European nations. Future GWAS with large series of ET patients will probably constitute an appropriate method to detect interesting regions and candidate genes involved in ET.

\section{Electronic sources}

HapMap: http://www.hapmap.org

National Centre of Biological Investigation (NCBI): http:// www.ncbi.nlm.nih.gov

Ensembl genome browser: http://www.ensembl.org UCSC Genome Bioinformatics: http://genome.ucsc.edu

\section{Acknowledgements}

This study was supported by grants from the German Federal Ministry of Education and Research (01GI0201) and from the Medical Faculty of the Kiel University. We are grateful to the DNA and Cell bank of the Neuroscience Federative Institute Paris for their help.

\section{References}

1 Louis ED, Ottman R: How familial is familial tremor? The genetic epidemiology of essential tremor. Neurology 1996; 46: 1200-1205.

2 Brin MF, Koller W: Epidemiology and genetics of essential tremor. Mov Disord 1998; 13: 55-63.

3 Louis ED: Etiology of essential tremor: should we be searching for environmental causes? Mov Disord 2001; 16: 822-829.

4 Louis ED: Essential tremor. Lancet Neurol 2005; 4: 100-110.

5 Deng H, Le W, Jankovic J: Genetics of essential tremor. Brain 2007; 130: 1456-1464.

6 Gulcher JR, Jonsson P, Kong A et al: Mapping of a familial essential tremor gene, FET1, to chromosome 3q13. Nat Genet 1997; 17: 84-87.

7 Higgins JJ, Pho LT, Nee LE: A gene (ETM) for essential tremor maps to chromosome 2p22-p25. Mov Disord 1997; 12: 859-864. 
8 Shatunov A, Sambuughin N, Jankovic J et al: Genomewide scans in North American families reveal genetic linkage of essential tremor to a region on chromosome 6p23. Brain 2006; 129: 2318-2331.

9 Lucotte G, Lagarde JP, Funalot B, Sokoloff P: Linkage with the Ser9Gly DRD3 polymorphism in essential tremor families. Clin Genet 2006; 69: 437-440.

10 Jeanneteau F, Funalot B, Jankovic J et al: A functional variant of the dopamine D3 receptor is associated with risk and age-at-onset of essential tremor. Proc Natl Acad Sci USA 2006; 103: 10753-10758.

11 Tan EK, Prakash KM, Fook-Chong S et al: DRD3 variant and risk of essential tremor. Neurology 2007; 68: 790-791.

12 Blair MA, Ma S, Phibbs F et al: Reappraisal of the role of the DRD3 gene in essential tremor. Parkinsonism Relat Disord 2008.

13 Lorenz D, Frederiksen H, Moises H, Kopper F, Deuschl G, Christensen K: High concordance for essential tremor in monozygotic twins of old age. Neurology 2004; 62: 208-211.

14 Nebel A, Croucher PJ, Stiegeler R, Nikolaus S, Krawczak M, Schreiber S: No association between microsomal triglyceride transfer protein (MTP) haplotype and longevity in humans. Proc Natl Acad Sci USA 2005; 102: 7906-7909.

15 Lorenz D, Papengut F, Frederiksen $\mathrm{H}$ et al: Evaluation of a screening instrument for essential tremor. Mov Disord 2008.

16 Fahn S, Tolosa E, Marin C: Clinical rating scale for tremor; in Jankovic J, Tolosa E (eds):: Parkinson's Disease and Movement Disorders. Baltimore: Williams \& Wilkins, 1993, pp 271-280.
17 Deuschl G, Bain P, Brin M: Consensus statement of the movement disorder society on tremor. Ad Hoc Scientific Committee. Mov Disord 1998; 13: 2-23.

18 Hampe J, Wollstein A, Lu T et al: An integrated system for high throughput TaqMan based SNP genotyping. Bioinformatics 2001; 17: $654-655$

19 De la Vega FM, Lazaruk KD, Rhodes MD, Wenz MH: Assessment of two flexible and compatible SNP genotyping platforms: TaqMan SNP Genotyping Assays and the SNPlex Genotyping System. Mutat Res 2005; 573: 111-135.

20 Teuber M, Koch WA, Manaster C, Wächter S, Hampe J, Schreiber $S$ : Improving quality control and workflow management in high-throughput single-nucleotide polymorphism genotyping environments. J Assoc Lab Autom 2005; 10: 43-47.

21 Cottingham Jr RW, Idury RM, Schaffer AA: Faster sequential genetic linkage computations. Am J Hum Genet 1993; 53: $252-263$.

22 Schaffer AA, Gupta SK, Shriram K, Cottingham Jr RW: Avoiding recomputation in linkage analysis. Hum Hered 1994; 44: 225-237.

23 Critchley M: Observations on essential (Heredofamilial) tremor. Brain 1949; 72: 113-139.

$24 \mathrm{Ma} \mathrm{S}$, Davis TL, Blair MA et al: Familial essential tremor with apparent autosomal dominant inheritance: should we also consider other inheritance modes? Mov Disord 2006; 21: $1368-1374$ 